\title{
Windows in early mammary development: critical or not?
}

\author{
Christopher H. Knight and Annette Sorensen \\ Hannah Research Institute, Ayr KA6 5HL, UK
}

\begin{abstract}
Two critical windows in mammary development have been proposed. The first arises from observations in rodents that nutrition during fetal and neonatal periods can affect mammary ductular outgrowth, subsequent proliferative activity and, eventually, tumorigenesis, that is, potentially it could have a long-term effect on pathological outcome (breast cancer) in women. The second similarly involves early diet, but in this case the outcome is phenotypic, in that dairy heifers reared too quickly during the peripubertal period subsequently show impaired udder development and reduced milk yield persisting throughout life. Most mammary development occurs during pregnancy, but this period is usually thought of only in terms of the immediate outcome for the subsequent lactation; it is not believed to be a critical window, at least in terms of lifetime mammary productivity. This review examines the evidence underlying these various claims and attempts to define the mechanisms involved, and also considers whether derangements occurring earlier in life (prenatally) could also have long-term consequences for physiological or pathological mammary development.
\end{abstract}

The mammary gland is unusual in that most of its development occurs in the adult, when it undergoes repeated cycles of development, function and dedifferentiation, involving extensive proliferation and apoptosis of secretory tissue (Knight, 2000; see Fig. 1). The physiological performance of the adult gland (amount of milk produced) is highly correlated with secretory tissue mass (Linzell, 1966). Although mammary primordia are present from early in embryonic life, the neonatal gland is poorly developed comprising, in rodents, a few branching ducts terminating in proliferative end buds (Anderson, 1978). Given the relative amounts of development at the different stages, it might appear that derangements of neonatal growth are unlikely to affect the performance of the adult gland. This feeling is reinforced, firstly, by the fact that much of prenatal mammary development is autonomous, and so is not likely to be influenced by external factors (Robinson et al., 1999) and, secondly, by the fact that the mature gland has the capacity for compensatory growth during lactation (Knight, 1997). Fetal and neonatal life is unlikely to be a critical window in mammary development. On the other hand, the secretory epithelial cells that proliferate during gestation do so on the ducts that have developed earlier in life, so it might seem inevitable that deficient ductular development will eventually impact on secretory tissue mass. The mammary duct system expands markedly during the peripubertal period and, in cattle, there is evidence that inappropriate nutrition will restrict this process and

Email: KnightC@hri.sari.ac.uk

This article is based on a presentation given at the British Society of Animal Science symposium 'Early Regulation of Mammalian Development' held in Aberdeen in September 2000. subsequently cause milk yield to be reduced (Sejrsen, 1994). Thus, a peripubertal critical window could certainly be proposed. There are two sets of potential interactions during gestation. As well as effects of the mother (and her environment) on fetal mammary development, there is the possibility that the fetus influences maternal mammary development. Given that the phenotypic expression of the mammary gland (milk) is for the benefit of the young rather than the mother, it is not surprising that this influence does occur: gestational mammogenesis is, in part, regulated by the fetoplacental unit through the production of the mammogenic hormone placental lactogen (Collier et al., 1995). Although gestational development is essential to lactational output, it is not a critical window in the classical sense of having an effect that is only manifest some considerable time later. However, gestational and lactational development and subsequent involution appear to alter permanently the responsiveness of the mammary gland to mitogenic stimuli and, by doing so, may have longterm effects on pathological development (Newcomb, 1997). Not only is the incidence of breast cancer lower in women who have breast-fed (Ing et al., 1977), there is also evidence that babies who have been breast-fed are less likely to develop the disease (Freudenheim et al., 1994). Furthermore, in rodents, maternal diet during gestation affects subsequent mammary tumorigenesis in female offspring (Hilakivi-Clarke et al., 1997b). This finding forces a re-evaluation of the potential impact of fetal and neonatal mammary growth; it is possible that they are critical windows in terms of pathological outcome. Lifetime mammary development is illustrated in Fig. 1, which incorporates the potential critical windows described. Since mammary developmental cycles persist throughout much 


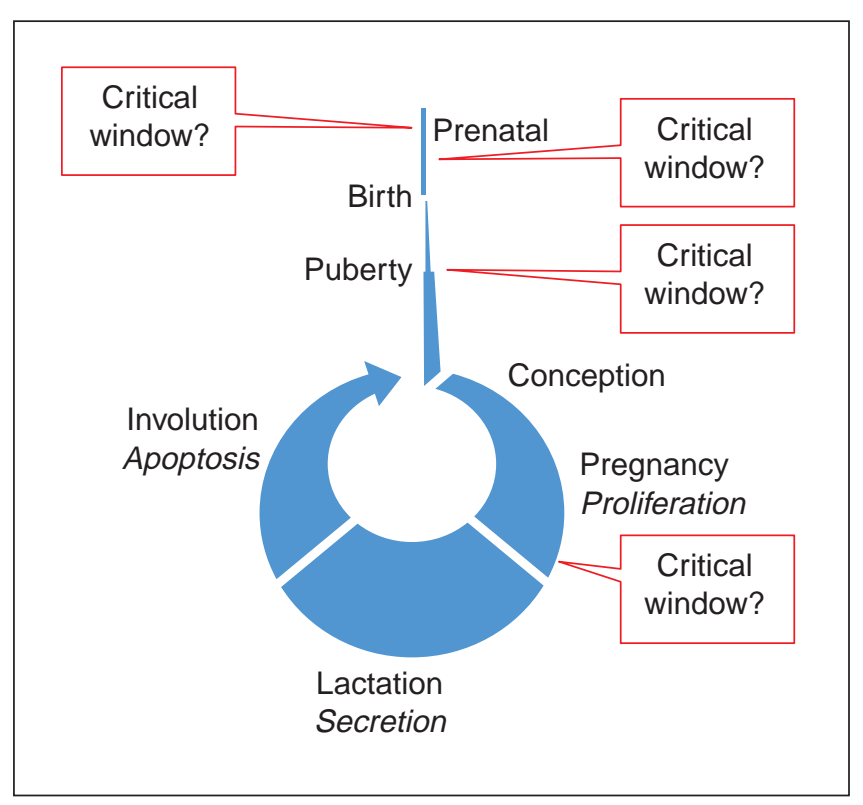

Fig. 1. Schematic representation of lifetime mammary development. The width of the arrow represents qualitatively the size of the gland. Proposed critical windows, points at which altered development could have a long-term effect, are shown by text boxes.

(or, in many species, all) of adult life, all four windows could be regarded as 'early' events and so will be included here. In the proper sense of 'early regulation of development' attention will be focused on the prenatal and neonatal windows.

\section{Embryonic and fetal mammogenesis}

There are a number of anatomical studies of fetal mammary development in farm species that now have to be regarded as historical (Raynaud, 1961; Anderson, 1978), and the process has also been studied ultrastructurally (Tobon and Salazar, 1974) and in terms of cell phenotype (Anbazhagan et al., 1998) in humans, but these observations are limited. Most quantitative data have been obtained in laboratory rodents (Robinson et al., 1999). In mice, the first evidence of individual mammary primordia are the mammary buds, which appear on the mammary lines (thickened ectodermal ridges running laterally from limb bud to limb bud) at days 10-11 of embryonic life (Daniel and Smith, 1999). These epithelial buds originate through accretion and migration of cells that have proliferated in the epidermis; the epithelium remains mitotically quiescent until days $12-13$. By this time, the mesenchyme immediately surrounding the bud has differentiated to form the primary mammary mesenchyme, which stimulates proliferative outgrowth of the bud to form the mammary sprout (days 15-16) and, by birth, a branching but still rudimentary ductal 'tree' (Robinson et al., 1999).

Factors that determine the 'normal' number and precise position of glands are unknown; the negative effects of androgens (see below) are arguably abnormal rather than normal. The interactions that occur between the epithelial and mesenchymal compartments are apparently sufficient to maintain and programme fetal mammary growth, since ductular elongation follows the normal timing and pattern when the rudiment is cultured in vitro (Robinson et al., 1999). Reciprocal co-culture experiments have established that primary mammary mesenchyme at day 12 will induce mammary differentiation in 'foreign' (non-mammary) epithelium, whereas at day 13 , mammary epithelium is able to induce non-mammary mesenchyme to differentiate into mammary mesenchyme (Kratochwil, 1969). This apparently clear-cut finding cannot be a full explanation, since a factor associated with the epithelial mammary bud clearly triggers the initial mesenchymal differentiation.

Although development is apparently autonomous, the fetal gland shows endocrine sensitivity. The classic example of this sensitivity is to be found in male rodents, most of which have no mammary tissue, as a result of another epithelial-mesenchymal interaction (Kratochwil and Schwartz, 1976). The epithelium induces androgen receptors in the mammary mesenchyme and as the fetal testes mature (at about day 13 or day 14 in mice) testosterone causes a condensation of mesenchyme around the neck of the mammary bud, which is 'nipped off' and regresses (Wasner et al., 1983). The mesenchyme also has oestrogen receptors, a point that will be considered later. The influence of male fetuses on sexual differentiation of adjacent female fetuses and vice versa has been reviewed by von Saal (1989). The most familiar agricultural example is the freemartin phenomenon in the female of mixed sex twin calves. More relevant to this discussion is the recent observation made in pigs that the number of teats (which varies considerably in this species) is inversely related to the male: female ratio in utero (Drickamer et al., 1999). The most likely explanation for this observation is that androgens produced by the male fetuses cause inhibition of development in some individual mammary glands in the female fetuses, as described for male mice. The process of androgen-mediated mammary destruction has not been studied recently and so it is not known whether the regression is necrotic (most likely) or involves programmed apoptosis. Selective apoptosis of core cells is certainly involved in cavitation, which converts the solid mammary sprout into a hollow duct. Further elongation of the ducts occurs by proliferation at the terminal end bud (TEB) (Robinson et al., 1999).

Several gene defects that prevent fetal mammary development have been identified. The earliest gene known to be expressed is the epidermal transcription factor Lef-1 and in its absence ductular outgrowth does not occur (Van Genderen et al., 1994). Ulnar-mammary syndrome is severe hypotrophy or complete absence of breast development in humans and appears to be associated with a defect in TBX3, a member of the $\mathrm{T}$ box family of transcription factors (Bamshad et al., 1997). However, the most studied defect is 


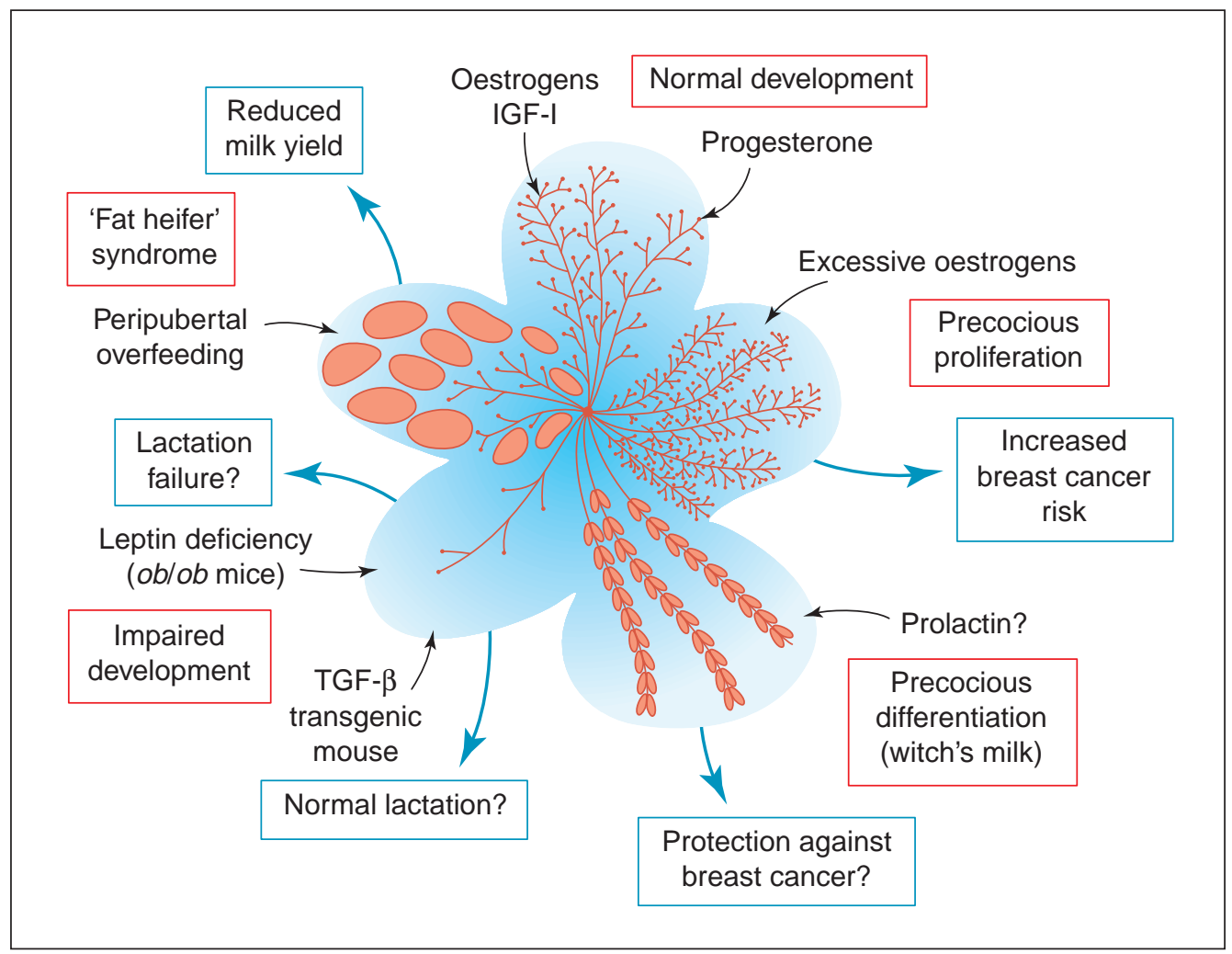

Fig. 2. Schematic representation of the various abnormalities that have been observed in neonatal mammary development and their potential consequences in adult life. The normal pattern of ductular extension stimulated by oestrogens (primary and secondary ducts) and progesterone (tertiary ducts and terminal end buds, TEBs) is shown at the top. Moving clockwise, fetal or neonatal exposure to excessive concentrations of oestrogens causes precocious proliferation of ducts and TEBs, which increases subsequent risk of tumours in rodent models. This situation is in contrast to precocious differentiation (bottom) in which TEBs develop into alveolar buds, which is exemplified by the occurrence of Witch's milk in human neonates. The stimulus is not well characterized but may involve prolactin, and there is some evidence to show that it affords protection against breast cancer. Impaired development of the duct system may or may not lead to depressed functionality; the examples cited in the text are overexpression of transforming growth factor $\beta$ (TGF- $\beta$ ), which subsequently can be rectified, and leptin deficiency, which cannot. Finally, in dairy cows, peripubertal overfeeding reduces the extent of ductular development and this reduces eventual milk yield.

in parathyroid hormone related protein (PTHrP), for which a knockout model is available (Dunbar and Wysolmerski, 1999). Knockouts are genetically modified animals in which the gene encoding a protein of interest (PTHrP in this case) has been deleted. PTHrP knockout mice express fetal lethality, but can be 'rescued' by re-expression of PTHrP specifically in the skeleton. By this means, PTHrP is now known to be involved in fetal development of a number of ectodermal tissues, including the mammary gland. PTHrP is normally expressed in mammary epithelium, whereas its receptor is located in the stromal mesenchyme (Dunbar and Wysolmerski, 1999). The knockout mouse has no mammary PTHrP and shows an absence of ductular development in that the mesenchyme is functionally incompetent, the usual sexual dimorphism disappears and, although mammary buds are present, the outgrowth of the sprout does not happen and the buds regress by birth. When a PTHrP-expressing transgene is reintroduced into the knockout mouse, development is rescued (Dunbar and Wysolmerski, 1999).

\section{Neonatal and peripubertal mammogenesis}

At birth, the murine mammary duct system is still rudimentary, comprising between 5 and 20 primary and secondary ducts. The major phase of ductular elongation and branching occurs at puberty at about 4 weeks of life and involves extensive proliferation to the point at which the duct system fills the entire mammary fat pad (Daniel et al., 1996). The combination of oestrogen and insulin-like 
growth factor I (IGF-I) is largely responsible for ductular elongation, whereas progesterone stimulates the slightly later development of tertiary side-branches (Atwood et al., 2000). Elongation and branching are by no means a random process and it was proposed some years ago that the patterning of the duct system was controlled by 'zones of inhibition' around each duct, into which other ducts would not grow (Faulkin and DeOme, 1960). This hypothesis has now been confirmed and the regulatory factor has been identified as transforming growth factor $\beta$ (TGF- $\beta$ ) (Daniel et al., 1996). Transgenic mice overexpressing TGF- $\beta$ have fewer, wider spaced ducts than wild-type mice and local implantation of TGF- $\beta$ into the fat pad creates around it an artificial inhibitory zone that growing ducts avoid. The proliferating epithelium interacts in a variety of ways with its surrounding extracellular matrix (ECM) (reviewed in Lochter and Bissell, 1997) and the growing epithelium produces TGF- $\beta$ only when it is in association with ECM. The growth potential of the TEB is explained by the fact that the layer of ECM that surrounds the duct is absent from the tip of the TEB, and so TGF- $\beta$ is not produced (Daniel et al., 1996).

The mouse may not be a good model of peripubertal mammary growth in other species. In dairy cows, some of the relationships among stromal adipose, ECM and epithelium appear to be different from those in rodents (Hovey et al., 1999). The importance of mammary fat is absolute: the growing duct system does not extend outside the fat pad in any species studied, but negative effects of excessive mammary fat on ductal extension have been recorded only in cattle (Sejrsen, 1994). The possibility of analogous effects in humans, in which peripubertal 'growth' clearly includes the deposition of significant quantities of mammary fat, is intriguing but as yet unknown. The limited extent of the neonatal duct system also means that rodents may not be a good model for studying the long-term impact of altered prenatal development, as the differences that could be achieved experimentally would be too small to quantify accurately. In only one species is there (subjective) evidence that prenatal development is both significant in amount and variable among individuals. Witch's milk is the name given to neonatal mammary secretion in human babies, both female and male. Although it has a long history (Forbes, 1950), Witch's milk has not been well studied. It is a milk-like secretion (Davies and Moncrieff, 1938), so is clearly evidence of differentiated mammary tissue. It is only ever present in small quantities, but opinions vary as to what proportion of babies produce the secretion. In one study, fluid could be expressed manually in 9\% (30 of 336) of infants examined at $\leqslant 1$ week of age (Madlon-Kay, 1986), whereas in earlier work fluid was obtained from $100 \%$ (18 of 18) of babies under 3 weeks of age and from $71 \%$ (75 of 106) of the total number that was sampled, including one baby as old as 19 weeks (Buehring, 1982). The reason for the difference is unknown and could simply relate to differences in technique, although the higher incidence of secretion was recorded in babies who were almost all being breast-fed, whereas the lower incidence was from a random population of unstated background. The endocrine explanation for Witch's milk has been given as the influence of maternal hormones on fetal mammogenesis (Lyons, 1937), but it is possible that bioactive factors in breast milk also play a part. Some pre-term infants who do not have breast nodules at birth develop them and start to secrete Witch's milk during the first few days or weeks of life (McKiernan and Hull, 1981a), and this early postnatal growth is correlated with serum prolactin concentration (McKiernan and Hull, 1981b).

\section{Mammogenesis in mouse knockout models}

Genetically modified knockout models, usually mice, are becoming more numerous. They are useful tools in physiological investigation, although they do have limitations with regard to revealing the presence of developmental critical windows. A defect arising during fetal life would not necessarily be the cause of a later abnormality, which could instead result from continued absence of the deleted factor. Therefore, a replacement strategy of some sort would be needed. To date, this is a largely theoretical consideration because apart from the gene defects mentioned above (which produce all-or-none effects), there does not appear to be a knockout model in which fetal mammary growth is impaired. Obvious candidates are hormones known to be involved in later mammary development, such as the steroids oestrogen and progesterone. Despite the fact that fetal mammary mesenchyme displays oestrogen sensitivity, oestrogen receptor knockout mice have normal neonatal glands (Bocchinfuso and Korach, 1997). The same is true of progesterone knockout mice (Humphreys et al., 1997), but this is less surprising since progesterone receptors are absent from rodent mammary tissue until a few weeks of age. Cyclin D1 is believed to mediate some of the mammogenic actions of the steroids, but again the knockout model has normal neonatal mammary tissue (Sicinski and Weinberg, 1997). Prolactin is involved intimately in differentiative development in mammary tissue and prolactin receptor knockout mice do not lactate but, as before, fetal mammary development is quite normal (Ormandy et al., 1997). Finally, IGF-I is a mammary mitogen but knockouts of IGF-I and of the IGF-I receptor both show normal fetal development (Hadsell and Bonnette, 2000). Although an IGF-II knockout mouse is available, no data have been published pertaining to its mammary development.

\section{Fetal and neonatal oestrogen exposure and breast cancer}

The fetal mammary mesenchyme possesses oestrogen receptors and experiments performed by Raynaud (1961) demonstrated significant effects of oestrogen on fetal mammary development. Oestrogen administered to the 
mother caused precocious fetal nipple development and partial or sometimes complete failure of ductular outgrowth. Clinical interest in a possible relationship between fetal oestrogen exposure and breast cancer later in life was triggered by observations that risk was greater in dizygotic twins and in infants with high birth weight, both of which are associated with increased intrauterine oestrogens, but was decreased in pre-eclamptic births, in which oestrogens are reduced. As a result, rodent models were developed in which the pregnant mother was treated with oestrogens or oestrogenic compounds, the female offspring were reared and subsequently exposed to a carcinogenic agent (usually dimethyl benzanthracene, DMBA) and the incidence of mammary tumours was noted (Rothschild et al., 1987). A recent study proposed that feeding a high-fat diet would have a similar effect, by increasing maternal oestrogen concentrations (HilakiviClarke et al., 1997b). This experiment included a group of rats in which the mother was treated with 20 ng oestradiol day $^{-1}$ between days 14 and 20 of gestation. Mammary development was measured in female offspring at days 22 and 47 of age using a morphometric scoring system. Duct growth was increased by oestrogen exposure at day 22, but this effect was not permanent: growth in the controls was equivalent by day 47. However, prevalence of TEBs was increased by oestrogen at both ages, although it is not known whether the effect persisted into old age. In contrast, the number of differentiated alveolar buds (ABs) was significantly reduced by oestrogen, also at both ages. TEBs are the main proliferative compartment of the pubertal gland, whereas $\mathrm{ABs}$ are characterized by an absence of proliferative cells, so the effect of fetal oestrogen exposure is to increase the proliferative potential within the pubertal and, possibly, adult gland. Other offspring were treated with DMBA at day 55 of age. The incidence of tumours remained low in control rats for the next 13 weeks and then increased gradually to a maximum of about $20 \%$ of individuals having at least one tumour. In oestrogen-exposed rats, the incidence of tumours increased gradually from week 3 onwards to reach $20 \%$ by week 13 and $50 \%$ by week 18 , a significant difference. In support of the main hypothesis, similar results were obtained with the high-fat diet (HilakiviClarke et al., 1997b), and others have obtained comparable data from treatment with diethylstilboestrol (Rothschild et al., 1987), the oestrogen agonist tamoxifen (Hilakivi-Clarke et al., 2000), chemicals that alter oestrogen action such as dioxin (Brown et al., 1998) and with oestrogens given neonatally (Hilakivi-Clarke et al., 1997a). The oestrogentreated neonatal mouse model was studied extensively in the 1970s (Mori et al., 1980), mainly in relation to vaginal cancer. Increased mammary tumorigenesis was a consistent finding, and it was proposed that part of the reason was that oestrogen exposure induced a permanent change in the sensitivity of the glands to mitogenic and lactogenic stimuli (Bern et al., 1992), although these data are less consistent. Vassilacopoulou and Boylan (1993) observed only small long-term changes in mice exposed to oestrogens during fetal development. The observations are generally supportive of the critical window concept, although another explanation is possible. Exposure of oestrogens during fetal development is often associated with aberrant pituitary function, increased prolactin and precocious puberty (Rothschild et al., 1987), all of which could be responsible for the later differences in mammary development and tumorigenesis. Nevertheless, the hypothesis could be advanced that circumstances or treatments that promote mammary differentiation early in life could have a longterm protective effect against breast cancer, whereas any factor that increases the proliferative potential of the glands could have the opposite effect. If so, the occurrence of Witch's milk described earlier assumes greater importance. As the secretion is the result of early mammary differentiation, might it be a physiological defence mechanism designed to protect against breast cancer?

\section{Parallels in later life: pregnancy, lactation and breast cancer}

If the hypothesis is indeed correct, lactation might be expected to protect against breast cancer, as it is the ultimate mammary differentiative state. There is growing evidence to support this theory, reviewed in Newcomb (1997). However, a different explanation has been put forward to explain this observation. It has been suggested that it is a local effect rather than a systemic endocrine effect, as shown by an elegant natural experiment. In the Hong Kong Tanka boat-dwellers, the incidence of cancer was found to be significantly higher in the left breast than in the right breast (Ing et al., 1977). These women habitually suckle only from the right breast, as dictated by the design of their traditional costume, so the effect was clearly one of breast-feeding. Removal of potential carcinogens in the milk was proposed as the mechanism, although no specific evidence was put forward to support this proposal.

Pregnancy has contrasting effects on the risk of breast cancer: pregnancy early in life is protective, whereas pregnancy late in life increases the risk (Kelsey et al., 1993). Most normal proliferation occurs during pregnancy and the fact that the new secretory tissue starts to differentiate may explain the protective effect. However, if the proliferation occurs later in life in a gland that has been programmed by earlier events to be 'at risk', the proliferation may be exactly the event that is needed to turn the risk into reality. Irrespective of whether terminal differentiation occurs (that is, whether the pregnant individual goes on to lactate), the tissue that has proliferated will at some stage involute through a process of apoptosis. It is possible that postapoptotic mammary tissue is less responsive to neoplastic stimuli, but this theory has not been tested.

A major difference between humans and most other mammals is the large number of oestrous cycles experienced. Adult cows spend most of their time either pregnant or lactating or both and do not suffer mammary cancer, whereas mouse models that spontaneously develop 
tumours typically do so late in a forcibly abstemious life. Mammary cells proliferate and involute during each recurring oestrous cycle, and we have investigated whether reproductive and lactational history has an effect on the extent of proliferation (Peris and Knight, 1997). It does. Proliferation was significantly lower in mice that had been pregnant than it was in virgins, but the lowest rate (by far) was recorded in mice that had been pregnant and had also lactated. Similar to the observation in the Tanka boat-dwellers (Ing et al., 1977), this was a local effect: teat-sealing experiments showed that the greatest protection was afforded to individual glands that had actually lactated. This finding accords with the hypothesis proposed: differentiation reduced the subsequent response of the gland to mitogenic stimuli.

Not only does breast-feeding protect the mother against breast cancer (Newcomb, 1997), it also appears to confer protection on the (female) baby. In an epidemiological study, breast cancer incidence was $55 \%$ in a bottle-fed population and $44 \%$ in a breast-fed population, a difference that was statistically significant (Freudenheim et al., 1994). Although the effect is relatively small, it has been confirmed in a separate study by an independent group (Potischman et al., 1995). The authors concluded that early nutrition alters mammary development in a way that has long-term effects, but they did not speculate on the precise biological mechanism. If the occurrence of Witch's milk is indeed greater in breast-fed infants, as indicated by the data of Buehring (1982), it is possible that there is a link between breast milk, precocious mammary differentiation and reduced risk of breast cancer.

\section{Early development and adult performance}

There is little data to indicate that aberrant fetal mammary development has a lasting effect on adult performance, in terms of capacity to produce milk. The observation of a reduced number of teats in pigs from a predominantly male litter (Drickamer et al., 1999) has not been followed through into effects on production, although a reduction in total yield would be anticipated.

In mice, the effects of impaired neonatal ductular outgrowth are quite variable, depending on the cause of the defect. Thus, transgenic mice overexpressing TGF- $\beta$ that show reduced duct growth subsequently develop normal lobuloalveolar secretory tissue during pregnancy and produce normal milk yields (Pierce et al., 1993). However, obese mice (ob/ob: a genetic mutant lacking leptin) appear to have poorly developed glands as juveniles and, when treated with leptin to bring about puberty and initiate and maintain a pregnancy, these animals fail to lactate normally (Chehab et al., 1996). These findings require some qualification. The apparently normal milk yield of the TGF- $\beta$ transgenic has not been quantified, it is merely an observation that normal-sized litters were reared. Furthermore, in other trangenic lines in which the TGF- $\beta$ gene was placed under the control of the pregnancy-responsive whey acidic protein (WAP) gene, lobuloalveolar growth was inhibited and lactation did not occur (Jhappan et al., 1993). Therefore, the effect of TGF- $\beta$ depends on when in the developmental cycle it is expressed.

Although it is clear that ob/ob mice do not undergo sexual maturation, impaired mammary development is a recent and, as yet, subjective observation of ours (A. Sorensen, R. G. Vernon and C. H. Knight, unpublished; Fig. 3 ) and, once again, no proper attempt has been made to quantify lactation, it is merely an observation that most litters die (Chehab et al., 1996). It is possible that leptin is not required for ductular growth, the defect being an indirect consequence of the failure to attain puberty. On the other hand, unless leptin is an obligate requirement for terminal differentiation and lactogenesis (and there is no evidence that it is) the failure of these animals to lactate would argue in favour of ductal development as a critical window, whereas the TGF- $\beta$ data indicate the opposite. There is no consensus.

In cattle, there is a widespread belief that peripubertal mammary development has a marked effect on subsequent milk yield. In an effort to reduce costs, farmers have gradually reduced the age at which they first breed their heifers, which has been achieved by increasing food intake and hence growth rate to advance puberty. Unfortunately, this practice is associated with reduced milk yield, an effect that often persists throughout life. Parallel but unrelated studies in the UK and USA in the late 1970s established that the rapid rearing caused a reduction in the ratio of ductular parenchyma: fatty stroma in the pubertal mammary gland, which translated through into a reduced mass of secretory tissue during lactation (Sejrsen, 1994). An endocrine explanation has been proposed for the reduced mammary growth (Weber et al., 1999). Overfeeding causes a reduction in growth hormone $(\mathrm{GH})$, and $\mathrm{GH}$ is known to be mammogenic in young animals. However, $\mathrm{GH}$ is not a mammary mitogen, rather it stimulates proliferation indirectly through IGF-I. Although $\mathrm{GH}$ is one factor responsible for stimulating IGF-I release it is not the only one, and overfed peripubertal heifers have high IGF-I despite their low GH. This is the opposite of what is needed, since it should be associated with increased, not decreased, mammary development. However, the action of IGF-I is modulated by a number of IGF-binding proteins (IGFBPs) (six in total), which can be stimulatory or inhibitory. One of these proteins, IGFBP-3, is upregulated in overfed heifers and is capable of blocking the mitogenic activity of IGF-I in vitro (Weber et al., 1999). The next step is to demonstrate that the required concentrations of IGF-I and IGFBP-3 are present within pubertal mammary tissue from normal and overfed heifers.

In a general sense, it is unsurprising that a reduction in ductular development should ultimately result in fewer secretory cells, since the secretory cells proliferate on the ducts. However, there is no mechanistic explanation for why the effect is permanent. If gestational mammogenesis is inhibited experimentally (by food restriction, for instance) the gland can increase its subsequent postparturient growth to rectify the shortfall, that is, compensatory mammary 
(a)

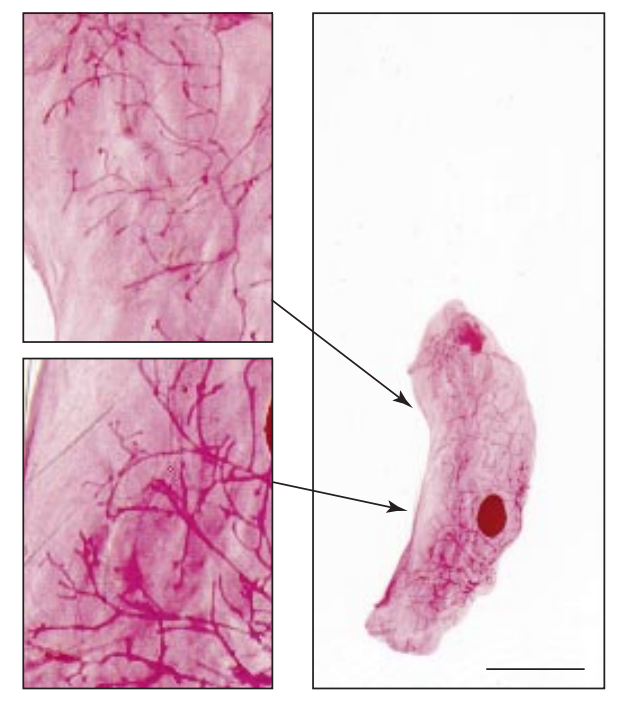

(b)

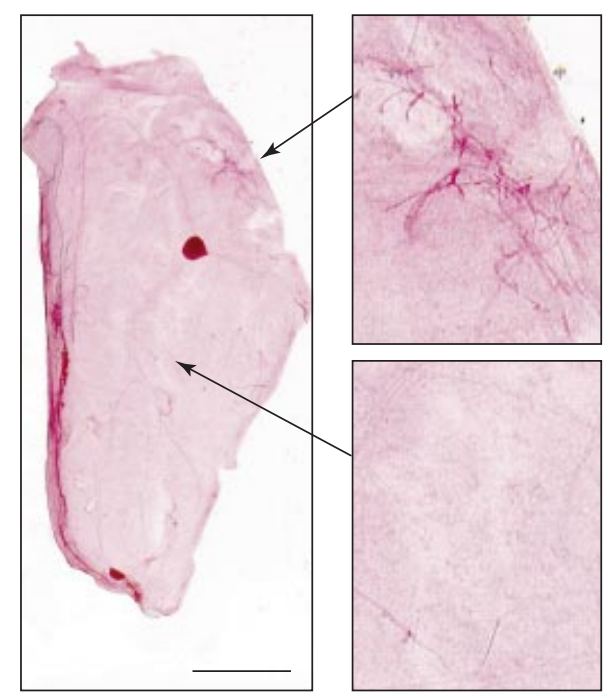

Fig. 3. Photomicrograph of mammary duct system from a normal pubertal mouse (a) and, to the same scale, from a leptin-deficient obese mouse of equivalent age (b). The magnified areas (all equivalent scale) show that in the normal mouse the duct system fills the entire fat pad, but in the obese mouse the enlarged fat pad contains only a limited number of ducts. Scale bars represent (a, b) $1.36 \mathrm{~cm}$.

development occurs (Knight and Peaker, 1982b). Similarly, in lactating goats, if one individual gland is surgically removed, the other will initiate compensatory growth in an effort to restore normal milk yield (Knight, 1987). Apparently, the mammary gland has a target mature size, which it tries to achieve if at all possible, but if the duct system is retarded it cannot do this.

There is another potential explanation for the adverse effects of peripubertal overfeeding, namely that the changes induced in metabolic hormones cause a switch in energy partitioning in favour of body reserves. In other words, the animal becomes inefficient and deposits fat at the expense of productive processes, initially lean growth and later lactation. In this scenario the reduction in milk yield would be the primary effect and the permanent shortfall in mammary secretory tissue the consequence, rather than the other way around. These hypotheses could be differentiated by rearing heifers at high and low rates and then, during their first lactation, treating them with the homeorhetic agent BST (bovine somatotrophin, or GH). A bigger milk yield response in the high growth rate heifers would be evidence of altered partitioning, especially if it were coupled with mammogenesis, since this would show that the gland was still capable of growth. We have conducted this type of experiment recently (C. H. Knight, B. Drew and K. Sejrsen, unpublished), but although the planned growth rates were achieved, the overfed heifers did not show the expected reduction in milk yield. The two groups of heifers also gave similar responses to a galactopoietic stimulus, which included clear evidence of mammary growth.

\section{Fetal and neonatal influences on maternal mammary development}

Although it has been stated that a mother does not appear to be able to influence mammary development in her female offspring in utero in a way that will eventually affect their potential to produce milk, what of the reverse? Can fetuses and neonates influence mammogenesis in their mother? There is good evidence that they can. Relationships between the number of fetuses carried and mammary growth and milk yield have been demonstrated in a number of polytocous species (sheep: Rattray et al., 1974; guineapigs: Davis, 1979; goats: Hayden et al., 1979). The effect is mediated through fetoplacental production of placental lactogen, which is mitogenic for mammary epithelial cells (Collier et al., 1993, 1995). Pregnant mice were hemihysterectomized to reduce the number of fetuses (Knight and Peaker, 1982a). This procedure inhibited mammogenesis significantly, but if a normal number of young was restored post partum, compensatory mammary growth ensured a normal milk yield. This finding demonstrates, firstly, that the fetal effect is not necessarily permanent and is not, therefore, evidence of a critical window and, secondly, that the influence of the young continues during early lactation. In mice, this influence may be mediated through increased prolactin release. In ruminants, there is little evidence to indicate a mammogenic role for prolactin (Knight, in press), but an effect of the suckling calf on mammary development and milk yield is still apparent (BarPeled et al., 1995). Furthermore, suckling has to happen 
only for the first few weeks post partum for an effect to be manifest throughout the lactation. A long-term action, but probably not a true critical window, in that the two events are not dissociated in time.

\section{Conclusions}

Evidence for critical windows in mammary development is convincing rather than entirely conclusive. A strong case can be made for links between perinatal mammogenesis and pathological development in later life, and given the high incidence of breast cancer in the developed world this topic is deserving of further study. The way that heifers are fed at puberty can certainly affect their eventual milk yield, but it will be difficult to establish whether this is truly through a permanent alteration of mammary development. It would certainly be of interest to attempt to modulate fetal mammogenesis in a dairy species, since it would be expected that the earlier duct growth is inhibited, the more likely it is to have a long-term effect.

\section{References}

Key references are identified by asterisks.

Anbazhagan R, Osin PP, Bartkova J, Nathan B, Lane EB and Gusterson BA (1998) The development of epithelial phenotypes in the human fetal and infant breast Journal of Pathology 184 197-206

*Anderson RR (1978) Embryonic and fetal development of the mammary apparatus. In Lactation: A Comprehensive Treatise pp 3-40 Ed. BL Larson. Academic Press, New York

Atwood CS, Hovey RC, Glover JP, Chepko G, Ginsberg E, Robison WG, Jr and Vonderhaar BK (2000) Progesterone induces side-branching of the ductal epithelium in the mammary glands of peripubertal mice Journal of Endocrinology 167 39-52

Bamshad M, Lin RC, Law DJ et al. (1997) Mutations in human TBX3 alter limb, apocrine and genital development in ulnar-mammary syndrome Nature Genetics 16 311-315

Bar-Peled U, Maltz E, Bruckental I, Folman Y, Kali Y, Gacitua H, Lehrer AR, Knight CH, Robinzon B, Voet H and Tagari H (1995) Relationship between frequent milking or suckling in early lactation and milk production of high producing dairy cows Journal of Dairy Science 78 2726-2736

Bern HA, Mills KT, Hatch DL, Ostrander PL and Iguchi T (1992) Altered mammary responsiveness to estradiol and progesterone in mice exposed neonatally to diethylstilbestrol Cancer Letters 63 117-124

Bocchinfuso WP and Korach KS (1997) Mammary gland development and tumorigenesis in estrogen receptor knockout mice Journal of Mammary Gland Biology and Neoplasia 2 323-334

Brown NM, Manzolillo PA, Zhang J-X, Wang J and Lamartiniere CA (1998) Prenatal TCDD and predisposition to mammary cancer in the rat Carcinogenesis 19 1623-1629

Buehring GC (1982) Short communication: Witch's milk potential for neonatal diagnosis Paediatric Research 16 460-462

Chehab FF, Lim ME and Lu R (1996) Correction of the sterility defect in homozygous obese female mice by treatment with the human recombinant leptin Nature Genetics 12 318-320

Collier RJ, McGrath MF, Byatt JC and Zurfluh LL (1993) Regulation of mammary growth by peptide hormones: involvement of receptors, growth factors and binding proteins Livestock Production Science $\mathbf{3 4}$ 21-33

Collier RJ, Byatt JC, McGrath MF and Eppard PJ (1995) Role of bovine placental lactogen in intercellular signalling during mammary growth and lactation. In The Hannah Symposium, Intercellular Signalling in the Mammary Gland pp 13-24 Eds CJ Wilde, M Peaker and CH Knight. Plenum, New York
*Daniel CW and Smith GH (1999) The mammary gland: a model for development Journal of Mammary Gland Biology and Neoplasia 4 3-8

Daniel CW, Robinson S and Silberstein GB (1996) The role of TGF- $\beta$ in patterning and growth of the mammary ductal tree Journal of Mammary Gland Biology and Neoplasia 1331-341

Davies WL and Moncrieff A (1938) Composition of the milk from the breasts of newly born infants Biochemical Journal 32 1238-1240

Davis SR (1979) Relative importance of pre-partum and post-partum factors in the control of milk yield in the guinea pig Journal of Dairy Research 46 613-621

Drickamer LC, Rosenthal TL and Arthur RD (1999) Factors affecting the number of teats in pigs Journal of Reproduction and Fertility 115 97-100

Dunbar ME and Wysolmerski JJ (1999) Parathyroid hormone-related protein A developmental regulatory molecule necessary for mammary gland development Journal of Mammary Gland Biology and Neoplasia $421-34$

Faulkin LJ and DeOme KBF (1960) Regulation of growth and spacing of gland elements in the mammary fat pad of the $\mathrm{C} 3 \mathrm{H}$ mouse Journal of the National Cancer Institute 24 953-969

Forbes TR (1950) Witch's milk and witches' marks Yale Journal of Biology and Medicine 22 219-225

Freudenheim JL, Marshall JR, Graham S, Laughlin R, Vena JE, Bandera E, Muti P, Swanson M and Nemoto T (1994) Exposure to breastmilk in infancy and the risk of breast cancer Epidemiology 5 324-331

Hadsell DL and Bonnette SG (2000) IGF and insulin action in the mammary gland. Lessons from transgenic and knockout models Journal of Mammary Gland Biology and Neoplasia 5 19-30

Hayden TJ, Thomas CR and Forsyth IA (1979) Effect of number of young born (litter size) on milk yield of goats: role for placental lactogen Journal of Dairy Science 62 53-57

Hilakivi-Clarke L, Cho E, Raygada M and Kenney M (1997a) Alterations in mammary gland development following neonatal exposure to estradiol, transforming growth factor $\alpha$, and estrogen receptor antagonist $\mathrm{ICl}$ 182,780 Journal of Cell Physiology 170 279-289

Hilakivi-Clarke L, Clarke R, Onojafe I, Raygada M, Cho E and Lippman M (1997b) A maternal diet high in $n-6$ polyunsaturated fats alters mammary gland development, puberty onset and breast cancer risk among female rat offspring Proceedings National Academy of Sciences USA 94 9372-9377

*Hilakivi-Clarke L, Cho E, Onojafe I, Liao DJ and Clarke R (2000) Maternal exposure to tamoxifen during pregnancy increases carcinogen-induced mammary tumourigenesis among female rat offspring Clinical Cancer Research 6 305-308

Hovey RC, McFadden TB and Akers RM (1999) Regulation of mammary gland growth and morphogenesis by the mammary fat pad: a species comparison Journal of Mammary Gland Biology and Neoplasia 4 53-68

Humphreys RC, Lydon JP, O'Malley BW and Rosen JM (1997) Use of PRKO mice to study the role of progesterone in mammary gland development Journal of Mammary Gland Biology and Neoplasia 2 343-354

Ing R, Ho JHC and Petrakis NL (1977) Unilateral breast-feeding and breast cancer Lancet 2 124-127

Jhappan C, Geiser AG, Kordon EC, Bagheri D, Hennighausen L, Roberts AB, Smith GH and Merlino G (1993) Targeting expression of a transforming growth factor $\beta 1$ transgene to the pregnant mammary gland inhibits alveolar development and lactation EMBO Journal 12 1835-1845

Kelsey JL, Gammon MD and John EM (1993) Reproductive and hormonal risk factors reproductive factors and breast cancer Epidemiological Reviews 15 36-47

Knight CH (1987) Compensatory changes in mammary development and function after hemimastectomy in lactating goats Journal of Reproduction and Fertility 79 343-352

Knight CH (1997) Compensatory mammary growth biochemical radar in regulation of tissue development. In Proceedings of the Hannah Symposium, Biological Signalling and the Mammary Gland pp 65-76 Eds CJ Wilde, M Peaker and E Taylor. Hannah Research Institute, Ayr

Knight CH (2000) The importance of cell division in udder development and lactation Livestock Production Science 66 169-176

Knight $\mathbf{C H}$ Overview of prolactin's role in farm animal lactation Livestock Production Science (in press) 
Knight CH and Peaker M (1982a) Mammary development in mice: effects of hemihysterectomy in pregnancy and of litter size post partum Journal of Physiology 327 17-27

Knight CH and Peaker M (1982b) Effects of fasting during mid-pregnancy or early lactation on mammary development and milk yield in mice Journal of Dairy Research 49 567-575

Kratochwil K (1969) Organ specificity in mesenchymal induction demonstrated in the embryonic development of the mammary gland of the mouse Developmental Biology 20 46-71

Kratochwil K and Schwartz P (1976) Tissue interactions in androgen response of embryonic mammary rudiment of mouse: identification of target tissue for testosterone Proceedings National Academy of Science USA 73 4041-4044

Linzell JL (1966) Measurement of udder volume in live goats as an index of mammary growth and function Journal of Dairy Science 49 307-311

Lochter A and Bissell MJ (1997) Mammary gland biology and the wisdom of the extracellular matrix. In Proceedings of the Hannah Symposium, Biological Signalling and the Mammary Gland pp 77-92 Eds CJ Wilde, M Peaker and E Taylor. Hannah Research Institute, Ayr

Lyons WR (1937) The hormonal basis for 'Witches' milk' Proceedings of the Society for Experimental Biology New York 37 207-209

McKiernan JF and Hull D (1981a) Breast development in the newborn Archives of Diseases in Childhood 56 525-529

McKiernan JF and Hull D (1981b) Prolactin, maternal oestrogens and breast development in the newborn Archives of Diseases in Childhood $\mathbf{5 6}$ 770-774

Madlon-Kay DJ (1986) Witch's milk American Journal of Diseases in Childhood $140252-253$

Mori T, Nagasawa H and Bern HA (1980) Long-term effects of perinatal exposure to hormones on normal and neoplastic mammary growth in rodents: a review Journal of Environmental Pathology and Toxicology 3 191-205

*Newcomb PA (1997) Lactation and breast cancer risk Journal of Mammary Gland Biology and Neoplasia 2 311-318

Ormandy CJ, Binart N and Kelly PA (1997) Mammary gland development in prolactin receptor knockout mice Journal of Mammary Gland Biology and Neoplasia 2 355-364

Peris S and Knight CH (1997) Effects of lactational history on estrousassociated cell proliferation in the mouse mammary gland Journal of Endocrinology 155 Supplement 2 OC18

Pierce DFJ, Johnson MD, Matsui Y, Robinson SD, Gold LI, Purchio AF, Daniel CW, Hogan BL and Moses HL (1993) Inhibition of mammary duct development but not alveolar outgrowth during pregnancy in transgenic mice expressing active TGF-beta 1 Genes and Development $72308-2317$

Potischman N, Brinton LA, Coates RJ, Malone KE and Schoenberg JB (1995) Exposure to breastmilk and risk of breast cancer Epidemiology 6 198-199

Rattray PV, Garrett WN, East NE and Hinman N (1974) Growth, development and composition of the ovine conceptus and mammary gland during pregnancy Journal of Animal Science 38 613-626

Raynaud A (1961) Morphogenesis of the mammary gland. In Milk the Mammary Gland and its Secretion pp 3-46 Eds SK Kon and AT Cowie. Academic Press, New York

*Robinson GW, Karpf ABC and Kratochwil K (1999) Regulation of mammary gland development by tissue interaction Journal of Mammary Gland Biology and Neoplasia 4 9-19

Rothschild TC, Boylan ES, Calhoon RE and Vonderhaar BK (1987) Transplacental effects of diethylstilbestrol on mammary development and tumorigenesis in female ACl rats Cancer Research 47 4508-4516

*Sejrsen K (1994) Relationships between nutrition, puberty and mammary development in cattle Proceedings of the Nutrition Society 53 103-111

Sicinski P and Weinberg RA (1997) A specific role for cyclin D1 in mammary gland development Journal of Mammary Gland Biology and Neoplasia 2 335-342

Tobon H and Salazar H (1974) Ultrastructure of the human mammary gland 1. Development of the fetal gland throughout gestation Journal of Clinical Endocrinology and Metabolism 39 443-456

Van Genderen C, Okamura RM, Farinas I, Quo RG, Parslow TG, Bruhn L and Grosschedl R (1994) Development of several organs that require inductive epithelial-mesenchymal interactions is impaired in Lef-1 deficient mice Genes and Development 8 2691-2703

Vassilacopoulou D and Boylan ES (1993) Mammary gland morphology and responsiveness to regulatory molecules following prenatal exposure to diethylstilbestrol Teratogenesis, Carcinogenesis and Mutagenesis 13 59-74

von Saal FS (1989) Sexual differentiation in litter-bearing mammals: influence of sex of adjacent fetuses in utero. Journal of Animal Science 67 1824-1840

Wasner G, Hennerman I and Kratochwil K (1983) Ontogeny of mesenchymal androgen receptors in the embryonic mouse mammary gland Endocrinology 113 1771-1780

Weber MS, Purup S, Vestergaard M, Ellis SE, Sondergard-Andersen J, Akers RM and Sejrsen K (1999) Contribution of insulin-like growth factor (IGFI) and IGF-binding protein-3 to mitogenic activity in bovine mammary extracts and serum Journal of Endocrinology 161 365-373 